\title{
OS PERÍODOS HISTÓRICOS DA PRODUÇÃO E APROPRIAÇÃO DO SOLO URBANO EM GOIÂNIA (GO)
}

\author{
The historical periods of urban land production and apropriation in Goiânia (GO)
}

Fábio de Souza*

Marlene Teresinha de Muno Colesanti **

*Acadêmico do PPG em Geografia - UFU - fbarqui@gmail.com. ** Docente da Universidade Federal de Uberlândia -

\begin{abstract}
Resumo: Objetivando relacionar os principais fatores de produção e apropriação do solo urbano, presentes desde a formação da atual capital de Goiás e que resultam em sua coeva situação, estrutura e organização, o presente trabalho procura esclarecer como essas mudanças, em um ou mais elementos que compõem o desenvolvimento da urbanidade em questão, podem explicar a brusca transformação desse município utilizando, para tal, uma revisão histórica de seu planejamento. 0 recorte temporal dessa revisão histórica abrange desde as diretrizes urbanísticas da fundação da capital goiana (1933) até o período de 2007-2015. Desse modo, o trabalho busca revisar e discutir os seis planos diretores presentes na urbanização da cidade e que contribuem para compreendermos a evolução do processo de ocupação da cidade.
\end{abstract}

Palavras-chave: Goiânia; plano diretor; urbanização.

\begin{abstract}
In order to relate the main factors of production and appropriation of urban land, present from conception of Goiás capital and leading to his current situation, structure and organization, this paper seeks to clarify how these changes, in one or more elements that make up the formation of this municipality, may explain the sudden transformation of this city using, for that, a historical review of its planning. The time frame of this historical revision incorporates the urban regulations of Goiás State capital, from his foundation (1933) until the years 2007-2015. Thus, this paper tries to review and discuss the six master plans present in the city, contributing to understanding the evolution of the city's occupation process.
\end{abstract}

Key-words: Goiânia; master plan; urbanization.

\section{Introdução}

0 presente trabalho visa relacionar os principais fatores de produção e apropriação do solo urbano, que se deram desde a formação da cidade de Goiânia, resultando em sua atual situação, estrutura e organização. Versar sobre planejamento urbano não é, por vezes, apenas registrar as modificações espaciais ocorridas na cidade, não constituindo o bastante para distinguir-se o processo histórico de estruturação ou reestruturação de uma urbe. Assim, faz-se necessário o esclarecimento de como essas mudanças, em um ou mais elementos que compõem o arcabouço da urbanidade em questão, geram mutações nos diversos setores da cidade.

\section{Desenvolvimento}


O tema ora estudado faz-se necessário pelo esclarecimento de como essas mudanças, em um ou mais elementos que compõem o arcabouço da urbanidade em questão, geram mutações nos diversos setores da cidade de Goiânia.

Foi com a ascensão ao poder de Getúlio Vargas, em 1930, que o processo de industrialização tornou-se o eixo norteador das discussões e medidas políticas no Brasil, muito em função da crise de 1929, que denotou o arquétipo da fragilidade da economia brasileira e serviu de aviso de que o país carecia diversificar sua produção. Durante essa conjuntura, o governo central tinha como diretriz política uma proposta de interiorização e integração nacional visando, principalmente, o suporte necessário para a instalação de uma nova ordem pretendida pelo movimento de 30.

Goiânia surge, nesse contexto, como consolidação de uma ideia de transformação e de ocupação do cerrado. Segundo o Instituto Brasileiro de Geografia e Estatística - IBGE (2015) esse processo se concretiza com o Decreto №. 3.359, de 18 de maio de 1933, que determinou a edificação da nova capital do estado de Goiás às margens e, através do Decreto №. 327, de 02 de agosto de 1935, organizou-se o município da nova capital, que recebeu o topônimo de Goiânia (GONÇALVES, 1984, p.10) e, a 06 de julho de 1933, o então interventor no governo estadual Pedro Ludovico Teixeira, através do Decreto №. 3.517, incumbe o arquiteto e urbanista Atílio Correia Lima como responsável pela elaboração do projeto da futura capital.

Segundo Sérgio Moraes, "a estrutura espacial urbana é, em última instância, um produto de acumulação" e, para analisar o caso, elaborou um estudo em um nível macro e outro micro. Em um universo macro, deve-se considerar o fato de que à Goiânia, na divisão nacional do trabalho, foi reservado um papel periférico, limitando seu processo decisório em nível local, já que seu espaço é definido, em última instância, em Brasília, "através da política econômica nacional e em São Paulo e outros centros decisórios menores, pelo comportamento dos agentes do capital privado".

Assim, o processo de formação do espaço de Goiânia deve ser examinado como produto sócio espacial de uma específica forma histórica e social de uma produção organizada de forma dependente, condicionada não só por relações locais existentes, mas também pelas relações nacionais e internacionais.

Na divisão social do espaço nacional, Goiânia funciona como um entreposto. Apenas parte do excedente é por ela apropriada, sendo que a maior parcela deste é encaminhada para os centros dominantes, favorecendo a reprodução do subdesenvolvimento da estrutura urbana e perpetuando sua dependência.

No que se refere ao comportamento das forças produtivas, dentro do nível micro, este se pode dividir em duas partes, sendo uma relacionada com a intensificação do uso (adensamento e expansão de ocupação) e outra com a expansão geográfica ou incorporação de novas áreas. Na expansão de Goiânia ao sul, são verificados dois processos: de avanço de espaços rarefeitos e ocupados. "No caso, com a intensificação de uso e aumento de densidade demográfica, com expansão vertical e produção do solo criado" (MORAES, 1991, p.32). Esses lugares, com altas densidades de ocupação por edifícios residenciais, influem no contexto da região sul de Goiânia e, consequentemente, na formação desse espaço.

Moraes (1991, p.32-45) divide a expansão imobiliária em quatro fases distintas, identificando tais fases de formação do espaço urbano, em Goiânia, com as fases de desenvolvimento "socioeconômico e político-ideológico do país":

1 a fase (1933 - 1950) - constitui-se na fase de criação do lugar, já que a cidade de Goiânia surge, definitivamente, em 1933. 0 espaço deve ter caráter social, já que o Estado utiliza a mudança da capital e a construção de uma nova cidade como embasamento político e plataforma de progresso e desenvolvimento, assim como estratégia de afirmação do poder.

Em meados de 1945 começa uma transição política no país, decorrente do fim da II Guerra Mundial - guerra essa que dificultou e atrasou em muito a construção de Goiânia. Em Goiás entra em 
cena, substituindo o grupo político de Pedro Ludovico Teixeira, o engenheiro Jeronymo Coimbra Bueno, eleito em 1947 e que governou até 1951. A instauração do espaço urbano de Goiânia obedeceu até 1950, ao Plano Piloto inicial (Figura 1), desenvolvido originalmente por Atílio Correia Lima e alterado por Armando Augusto de Godoy,

[...] com a interferência da firma Coimbra Bueno e Cia Ltda., que aprovou em julho de 1938 a Vila Coimbra, como satélite de Campinas. Com forte controle do estado, a cidade expandiu ao sul, em direção às áreas pertencentes ao estado, e a oeste, em direção à área da firma Coimbra Bueno e Cia Ltda. (MORAES, 1991, p.36).
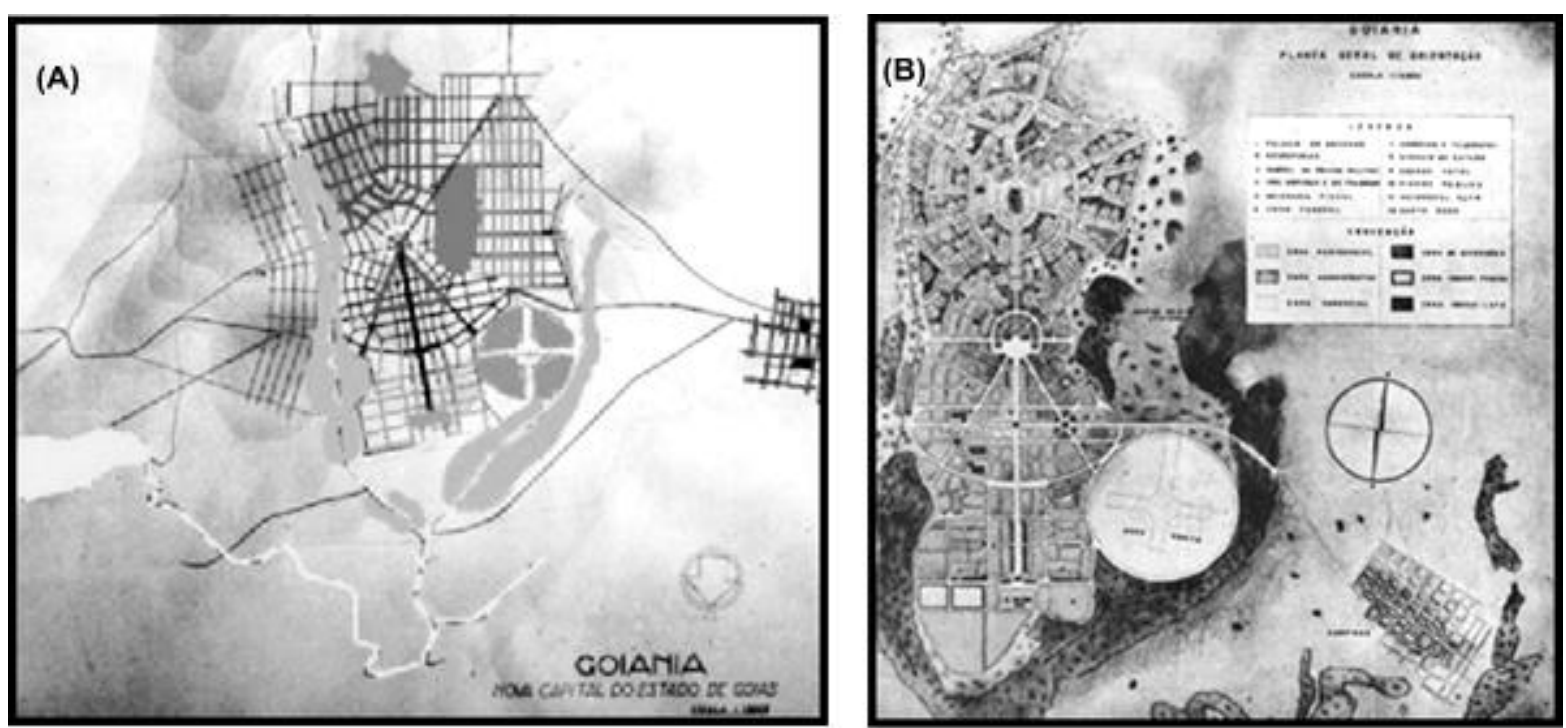

Figura 1. Plano Diretor de Goiânia, original de Atílio Corrêa Lima, (A), e Planta Geral de Orientação de Goiânia, de Armando Augusto de Godoy, (B)

Fonte: Diniz, p. 123 e 205. Brasília, 2007.

Por volta de 1950 a população de Goiânia chegava a 53.000 habitantes, com a equivalência de 10.600 residências já, então, aproximando-se dos 12.00 lotes previstos em projeto, numa área, adquirida pelo estado, capaz de comportar 48.300 lotes, sendo a maioria deles ao sul do plano inicial - núcleo central.

$2^{\text {a }}$ fase (1950 - 1964) - é denominada, segundo Moraes (1991, p.38), de "fase de ampliação do espaço", já que nesse período os latifundiários que, de forma consentida pelo poder público, haviam estocado terras no entorno da cidade, parcelaram extensivamente suas glebas, beneficiando-se do capital social. No censo de 1960 a população de Goiânia havia triplicado em relação ao anterior, atingindo 151.000 habitantes e alcançando, em 1964, a marca de 260.000 habitantes, ou seja, cinco vezes maior que em 1950.

Isso gerou um mercado para 40.000 novas moradias, aproximadamente, acarretando uma especulação imobiliária, já que o impacto dessa demanda teve repercussões fundamentais sobre a organização socioeconômica da cidade e, principalmente, na sua estruturação.

A liberação para construções nos setores então periféricos (Sul, Oeste, Vila Coimbra, Vila Nova e Leste Universitário), além da dispensa das exigências de infraestrutura para loteamentos privados, ocasionou a aprovação de Grande número de novos parcelamentos ativando, assim, o círculo imobiliário. Foram aprovados, nesse período que vai de 1950 a 1964, 183 loteamentos, de maneira aleatória e sem elos entre si, o que acarretou uma ocupação rarefeita, sem uma composição com a malha urbana existente. Os loteamentos aconteciam de forma descontrolada. Dos 671 parcelamentos constantes hoje, no Cadastro Técnico Municipal da Secretaria Municipal de Finanças - SEFIN (2015), 183 foram implantados nessa fase. Ou seja, em um período de 14 anos, dos 82 anos de existência da 
nova capital, $27,27 \%$ de seus loteamentos foram aprovados e implantados, sem infraestrutura (Figura 2).
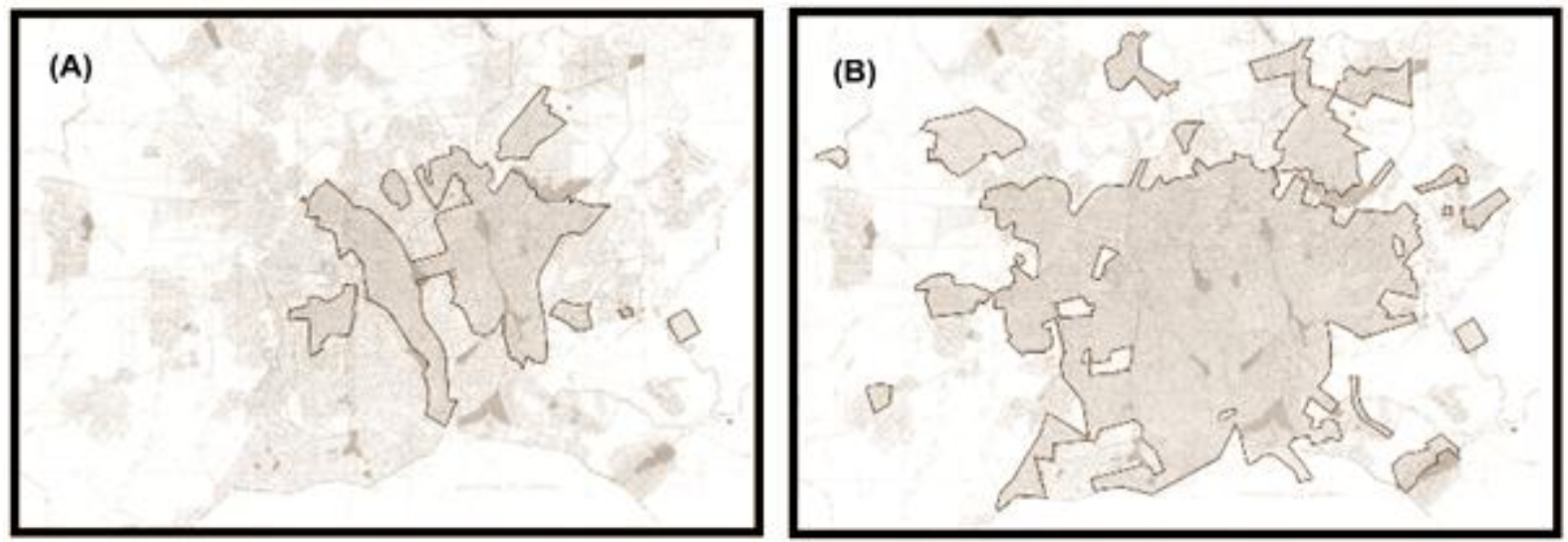

Figura 2. Evolução dos loteamentos em Goiânia. (A), até 1951 e (B) até 1959

Fonte: Ribeiro, 2004, p. 41.

O sistema viário estruturou esse processo de expansão urbana. Surgiu, então, uma tendência de adensamento da faixa vazia de solo urbano, entre os setores Sul e Oeste e também a leste (Vila Redenção) e a oeste (Vila União), com o crescimento tendendo para os bairros ao sul da Avenida Anhanguera.

A prefeitura de Goiânia, no ano de 1959, contratou os serviços do urbanista Luis Saia, a fim de estabelecer um novo plano de expansão para a cidade, o que findou gerando as diretrizes para a criação da cidade industrial.

3a fase (1964 - 1975) - Em 1967 é elaborado, por uma comissão coordenada pelo arquiteto e urbanista Jorge Wilheim, o Plano Diretor de Desenvolvimento Integrado de Goiânia - PDIG. O PDIG estabeleceu diretrizes e medidas, grande parte delas não implantadas, recuperou a obrigatoriedade da infraestrutura básica quando da aprovação de parcelamentos urbanos e resultou, ainda, na criação de um órgão de planejamento municipal (Superplan, posteriormente Instituto de Planejamento - IPLAN).

4 a fase (1975 - 1985) - È neste período que ocorre uma das fases mais acentuadas de adensamento populacional no estado e na cidade. De acordo com o anuário estatístico do IBGE em 1985, o estado de Goiás apresentava uma das maiores taxas de crescimento populacional e imigratório (Quadro 1).

\begin{tabular}{|c|c|c|c|c|c|c|c|c|c|c|c|c|}
\hline \multicolumn{10}{|c|}{ TAXA MEDIA ANUAL DE CRESCIMENTO POPULACIONAL } & \multicolumn{3}{|c|}{$\begin{array}{c}\text { TAXA DE IMIGRAÇĀO } \\
(\%)\end{array}$} \\
\hline \multirow{2}{*}{$\begin{array}{l}\text { Grandes Regiōes/Unidade da } \\
\text { Federação }\end{array}$} & \multicolumn{3}{|c|}{$1950 / 1960$} & \multicolumn{3}{|c|}{$1960 / 1970$} & \multicolumn{3}{|c|}{$1970 / 1980$} & \multirow[b]{2}{*}{1960} & \multirow[b]{2}{*}{1970} & \multirow[b]{2}{*}{1980} \\
\hline & Total & Urbana & Rural & Total & Urbana & Rural & Total & Urbana & Rural & & & \\
\hline Brasil & 2,99 & 5,15 & 1,55 & 2,89 & 5,22 & 0,57 & 2,48 & 4,44 & 0,62 & 12,33 & 14,15 & 15,29 \\
\hline Norte & 3,34 & 5,04 & 2,37 & 3,47 & 5.44 & 2,11 & 5,02 & 6.44 & 3,70 & 9,72 & 9,90 & 18,10 \\
\hline Nordeste & 2,08 & 4,63 & 1,02 & 2,40 & 4,57 & 1,10 & 2,16 & 4,10 & 0,53 & 6,31 & 5,93 & 6,49 \\
\hline Sudeste & 3,06 & 4,91 & 1,06 & 2,67 & 5,19 & 1,88 & 2,64 & 3,99 & 2,00 & 13,71 & 16,57 & 18,45 \\
\hline Sul & 4,07 & 6.44 & 2,90 & 3,45 & 5.29 & 2,20 & 1,44 & 4,98 & 2,48 & 16,83 & 17,50 & 14,06 \\
\hline Centro-Oeste & 5,36 & 8,90 & 3,89 & 5,60 & 9.24 & 3,14 & 4,05 & 7,69 & 0,81 & 29,38 & 32,84 & 35,14 \\
\hline Goiás & 4,62 & 8,73 & 3,22 & 4,38 & 7,96 & 2,43 & 2,76 & 6,86 & 1,53 & 26,95 & 25,21 & 23,17 \\
\hline
\end{tabular}

Quadro 1. Resumo dos dados do Anuário Estatístico do Brasil de 1985 do IBGE

Fonte: Elaborado pelo autor com base em dados coletados em SOUZA, 1992. p.60-61.

Este período é marcado, também, pelas repercussões da criação, em nível nacional, do Instituto 
Brasileiro do Transporte Urbano (IBTU) e, em nível municipal, da Empresa de Transporte Urbano de Goiás S/A (TRANSURB), influenciando, no desenvolvimento das cidades do entorno - especialmente as das regiões sul e oeste - pelo processo de conurbação e consequente periferização ${ }^{1}$.

Assim, a expansão na rede de transportes integra as atividades intermunicipais tendo Goiânia como polo de atração, juntamente com a transformação do solo rural em urbano, resultado da interação funcional entre os municípios. Mas se por um lado houve um acelerado crescimento demográfico e interação entre Goiânia e os municípios circunvizinhos, por outro não houve um acompanhamento da infraestrutura de serviços básicos.

As quatro fases identificadas por Sérgio Moraes (1991) são recortes temporais que o autor utilizou para compreensão do processo de ocupação e expansão urbana da cidade de Goiânia. Porém, o Município de Goiânia viveu, ao longo de sua trajetória, seis planos diretores de desenvolvimento: o primeiro concluído e oficializado em 1938; o segundo concluído, mas não oficializado, no período de 1959 a 1962; o terceiro desenvolvido no período de 1967 a 1979; o quarto, desenvolvido de 1989 a 1992 e oficializado em 1994. O PDIG 2000 e o Plano Diretor de Goiânia publicado em 2007 são, respectivamente, o quinto e o sexto (GOIÂNIA, SECRETARIA MUNICIPAL DE PLANEJAMENTO E URBANISMO, 2008).

Assim, seguindo a lógica dessas quatro fases distintas da expansão imobiliária, identificadas pelo autor citado anteriormente, e que representam a formação do espaço urbano em Goiânia, sob uma óptica socioeconômica e político-ideológica do país, e considerando os planos diretores posteriores ao trabalho de Moraes, pode-se depreender e analisar mais dois períodos.

1 o período (1986 - 2007) - Essa fase é caracterizada pelo emprego, no planejamento urbano, dos princípios resultantes das mudanças ocorridas durante o período de redemocratização brasileira na década de 1980, onde novas demandas socioeconômicas foram instituídas pela Constituição da República Federativa do Brasil (CFRB), em 1988, e posteriormente pelo Estatuto da Cidade, Lei №. 10.257 de 2001.

Desde 1988, com a promulgação da CFRB/88, os municípios têm como responsabilidade a elaboração de seus planos diretores (BRASIL, CFRB, 1988), sendo que os artigos №. 182 e 183 da referida Constituição, que tratam da matéria planejamento urbano, somente foram regulamentados em 10 de julho de 2001 pela Lei №. 10.257/2001.

Coordenado pela Empresa Engevix Engenharia S/A, em 1992 foi elaborado o Plano de Desenvolvimento Integrado de Goiânia (PDIG-2000), que viria ser oficializado em 1994. 0 plano caracterizou-se pela intervenção no zoneamento e uso do solo da cidade e marcou o retorno da obrigatoriedade de implantação de infraestrutura pelo agente imobiliário.

Notoriamente o PDIG reunia princípios voltados para a execução da função social da propriedade no planejamento do município, a partir de instrumentos jurídico-urbanísticos. Focado no planejamento estratégico, simbolizou um período novo no planejamento urbano da cidade, congregando alguns instrumentos estabelecidos pela CFRB/88.

O solo criado veio ser utilizado após o Zoneamento de 1994, consolidando a transformação e verticalização iniciada na segunda metade dos anos 1980, dos setores Bueno e Bela Vista, muito em função das pressões dos agentes imobiliários, e às melhorias na infraestrutura dos bairros, originadas pela prefeitura, no fim dos anos 1970. Segundo Miranda (2011, p.17) o plano de 1992 "trouxe grandes mudanças, entre elas diretrizes norteadoras das políticas socioeconômicas, físicoterritoriais, culturais, institucionais e administrativas".

Porém, a despeito da alocução de participação popular nas decisões, previsto pela CRFB/88, assim como ocorrido nas demais áreas urbanas brasileiras houve uma viabilização de um "planejamento implícito e ideológico de obras com grande participação do setor imobiliário, especialmente as

\footnotetext{
1 Segundo pesquisa realizada pelos autores junto à biblioteca da Secretaria de Planejamento Urbano e Habitação - SEPLANH, antigo IPLAN, em 1960 a população do entorno de Goiânia correspondia a 11,3\% da população total do estado, crescendo para $16,2 \%$ em 1970 e, em 1980 , para $22,3 \%$.
}

ParaOnde!?, Porto Alegre, v.9, n.2, p.94-101, 2018. Edição Especial: XII ENANPEGE http://seer.ufrgs.br/paraonde 
empresas vinculadas a obras públicas" (PDIG, 1992, apud. LIMA, 2011, p.99). Segundo Lima, 2011, “a expansão da rede sanitária e a pavimentação das ruas tornaram viável a construção vertical em toda a cidade e os Projetos Diferenciados de Urbanização - PDU foram intensificados nas áreas mais periféricas" (LIMA, 2011, p.99).

É importante consideramos que, nesse período, Goiânia incursa no rol das metrópoles brasileiras com mais de um milhão de habitantes, atingindo em 2000, segundo estimativas do IBGE (2015), aproximadamente 1,093 milhão de habitantes. Sua região metropolitana possui 20 municípios com área territorial de $7.397,20 \mathrm{~km}^{2}$ e, de acordo com o Censo 2010, abriga uma população de 2.173 .141 pessoas (BRASIL, IBGE, 2010).

Todavia, se nas décadas anteriores a migração possuía um caráter mais intrarregional e intrametropolitana, com "contingentes expressivos de migrantes" (MOYSÉS et al., 2007, p.7), a partir dos anos 90, essa migração adveio a sustentar características inter-regionais, instigando ainda a migração para o seu entorno.

Como reflexo das diferenças no zoneamento e consequente produtividade do solo, o valor da renda desse solo em Goiânia eleva, especialmente nas novas centralidades que surgem nos eixos viários de desenvolvimento urbano, em pontos onde o monopólio da terra se encontrava nas mãos dos agentes imobiliários e de uma população cujo capital privado lhes proporcionava condições para especulação do solo criado. Assim, de acordo com Oliveira e Peixoto (2009),

[...] a fisionomia peculiar de Goiânia, definida pelas suas referências urbanísticas iniciais, alterou-se rapidamente espelhando-se em São Paulo, que por sua vez, repetia a congestão de Manhattan (OLIVEIRA e PEIXOTO, 2009, p. 61).

Podemos observar, dessa forma, que no período compreendido de 1986 a 2007 e em uma conjuntura de profundas alterações econômicas e sociais que caracterizavam a realidade do planeta e, por conseguinte do Brasil, o PDIG-2000, de 1992, ainda se baseava no processo de ordenamento territorial por meio, sobretudo, da legislação de uso e ocupação do solo baseada em zoneamentos.

$2{ }^{\circ}$ período (2007 a 2015) - De acordo com Moysés et al. (2007),

[...] passados mais de 10 anos, com o advento do Estatuto da Cidade (Lei 10.257 de 10 de julho de 2001), o PDIG-2000 passou por uma revisão cujo prazo deveria se esgotar em agosto de 2006. (MOYSÉS et al., 2007, p.7).

Baseado em um relatório preliminar abrangendo informações técnicas norteadoras do cenário a ser adotado na construção da Política Urbana do Município, o novo Plano Diretor de Goiânia - PDIG2007 - define os seguintes temas: modelo espacial; perímetro urbano; macrozoneamento da área urbana e rural; macro rede viária básica; sistema de transporte coletivo; desenvolvimento econômico; programas especiais; e vazios urbanos (GOIÂNIA, 2007).

A despeito dos objetivos contidos em sua premissa, e já passados quase uma década desde sua publicação, pouco do novo plano diretor foi concretizado. A exceção se dá: (a) em alguns projetos em Áreas de Especial Interesse Social - AEIS, como forma de promoção de políticas habitacionais, muito em função do programa do Governo Federal nomeado "Minha Casa Minha Vida"; (b) na construção de alguns corredores para o transporte coletivo, modal ônibus, e que não seguiram o que estava previsto no próprio plano. Depreende-se, assim, que o próprio poder municipal não segue o disposto no Plano Diretor de Goiânia.

Mesmo essas exceções possuem cunho mercadológico e representam os agentes imobiliários que sempre se apropriaram das políticas públicas em benefício próprio, reproduzindo ou a velha dicotomia da ocupação das áreas periféricas, no caso dos programas de habitação, ou seus interesses 
na valorização do solo urbano, pela liberação de uso, quando da implantação dos referidos corredores de transporte público, uma vez que ao longo desses eixos foi incentivado o adensamento.

Ainda nesse período, entre os anos de 2010 a 2013, vale ressaltar que o Brasil passou por um forte crescimento econômico, impulsionado por conjunturas internacionais que, aliado ao novo PDIG-2007, refletiu de forma incisiva na produção e apropriação do solo urbano em Goiânia. 0 acréscimo da renda per capita gerou um crescimento exponencial no consumo, que resultou no aumento da aquisição de imóveis e, especialmente, em acréscimo da frota de veículos.

Com relação aumento da frota de automóveis, de acordo com a ANTP - Associação Nacional de Transportes Públicos (1999) “(...) as maiores cidades brasileiras, assim como muitas grandes cidades de países em desenvolvimento, foram adaptadas nas últimas décadas para o uso eficiente do automóvel (...)" cuja frota cresce acentuadamente. Esse padrão de mobilidade baseado no uso intensivo de transporte motorizado individual acarreta uma série de externalidades negativas para o município de Goiânia, com destaque para os problemas ambientais, as perdas de tempo com os congestionamentos urbanos e o aumento dos acidentes de trânsito.

Em razão do acréscimo na frota de veículos, que impulsionou a população para os municípios do entorno, a aglomeração de Goiânia tomou proporções cada vez maiores, debruçando-se sobre o território das cidades limítrofes. Como consequência, o município de Goiânia passou a exibir diferentes dificuldades quanto à mobilidade urbana. Viver e trabalhar na cidade de Goiânia vem se tornando cada vez mais complicado, em grande parte, pela dificuldade em movimentar-se dentro dela.

Os municípios do entorno não resistiram à pressão pelo solo e à dependência do polo concentrador dos atributos urbanísticos de uma grande cidade e findaram por se unificar à malha urbana de Goiânia. Com isso, da fundação até os dias atuais "Goiânia vem sofrendo mudanças geradas pela alteração no tipo de uso e ocupação do solo" (MANSO, 2002), bem como nas possibilidades de deslocamentos ou viagens realizadas na região urbana.

Quanto à questão imobiliária, o Artigo 70 do PDIG-2007 priorizou a urbanização e densificação da cidade construída e, em seu Artigo 110-A, retirou as limitações quanto às alturas máximas das edificações (GOIÂNIA, PDIG-2007, p.57, 65,66).

Essa densificação e não limitação quanto à altura máxima alterou significativamente a paisagem urbana. Os bairros passaram a abrigar grandes empreendimentos imobiliários com alturas bem acima das pré-existentes. As edificações, que dificilmente ultrapassavam os 20 pavimentos, passaram a contar com 30, 40 e, mais recentemente, alguns empreendimentos anunciaram 50 pavimentos, cunhando uma paisagem cosmopolita que procura recriar modelos internacionais do poder e do dinheiro.

\section{Considerações Finais}

Por meio do processo de ocupação que Goiânia sofreu ao longo dos anos e uma vez que a cidade relativamente nova, sua paisagem apresentou constante construção e reconstrução, refletindo em um processo de configuração de seu panorama e sua identidade.

Uma análise retrospectiva dos planos diretores de Goiânia possibilita verificar quais foram os alicerces das intervenções no ordenamento territorial da cidade e em quais ocasiões o poder público municipal, em detrimento do controle do progresso da urbe, altera as normas legais vigentes em favor dos zeles do capital privado.

\section{Referências}


BRASIL. Constituição da República Federativa - CRF. Departamento de Imprensa Nacional, Brasília, 1988.

Instituto Brasileiro de Geografia e Estatística - IBGE -. Biblioteca digital, Brasília, 2015. (Disponível em: < http://biblioteca.ibge.gov.br/visualizacao/dtbs/goias/goiania.pdf>. Acesso em 25 de novembro de 2015.

Instituto Brasileiro de Geografia e Estatística - IBGE - Evolução populacional do município de Goiânia - Censo Demográfico 1991, Contagem Populacional 1996, Censo Demográfico 2000, Contagem Populacional 2007 e Censo Demográfico 2010; Brasília, 2015. Disponível em: http://www.cidades.ibge.gov.br/painel/populacao.php?codmun $=520870 \&$ search=\%7Cgoiania\&lang=> Acesso em 25 de novembro de 2015.

GOIÂNIA, Secretaria Municipal De Planejamento e Urbanismo - SEPLAN. Plano de Desenvolvimento Integrado de Goiânia - PDIG 2000. “s.n.”, Goiânia, 1992.

Secretaria Municipal De Planejamento e Urbanismo - SEPLAN. Lei Complementar nำ171, de 29 de maio de 2007. [s.p.], Goiânia, 2007.

Secretaria de Finanças - SEFIN. Cadastro Técnico Municipal da Secretaria Municipal de Finanças. "s.n.", Goiânia, 2015.

GONÇALVES, N. N. Evolução do planejamento urbano de Goiânia - perspectiva histórica. Cadernos do Indur. "s.n.", n. 4, Goiânia, 1984.

MANSO, C. F. A. Goiânia - uma concepção urbana, moderna e contemporânea - um certo olhar. [s.p.], ed. do autor, Goiânia, 2002.

MIRANDA, R. Goiânia - As Parcerias Público Privadas e as Zonas De Interesse Urbanístico / Áreas Especiais de Interesse Urbanístico. Dissertação (Mestrado Multidisciplinar em Sociedade, Tecnologia e Meio Ambiente) - Centro Universitário De Anápolis - Unievangélica, Anápolis - GO, 2011. (Disponível em: < http://www.unievangelica.edu.br/files/images/Rosangela\%20de \%20Miranda.PDF>. Acesso em 21 de novembro de 2015).

MORAES, S. O Empreendedor Imobiliário e o Estado: o processo de expansão de Goiânia em direção sul (1975-1985). Dissertação (Mestrado em Arquitetura e Urbanismo) - Universidade de Brasília, [s.p.], Brasília, 1991.

MOYSÉS, A.; SILVA, E. R.; BORGES, E. M.; RIBEIRO, M. G. Da formação urbana ao empreendedorismo imobiliário: A nova face da Metrópole Goianiense. Revista Mercator - Revista de Geografia da Universidade Federal do Ceará. Volume 06, no 12, 2007 (37-50). Disponível em: <http://www.observatoriodasmetropoles.net/download/gthab/Textos_ref/04_Ary_ lcileni.pdf>. Acesso em 25 de novembro de 2015.

OLIVEIRA, A. M. V.; PEIXOTO, E. R. Estudos de bairros: entre a arquitetura e a história. Revista Mosaico - Revista do Mestrado em História da PUC Goiás, v.2, n.1, p.59-67, 2009. Disponível em: <seer.ucg.br/index.php/mosaico/article/download/783/600> Acesso em 23/12/2015. 